\title{
Evaluation of the forest growth model SILVA along an elevational gradient in Switzerland
}

\section{Journal Article}

\section{Author(s):}

Schmid, Stéphanie; Zingg, Andreas; Biber, Peter; Bugmann, Harald

Publication date:

2006-03

Permanent link:

https://doi.org/10.3929/ethz-b-000037384

\section{Rights / license:}

In Copyright - Non-Commercial Use Permitted

Originally published in:

European Journal of Forest Research 125(1), https://doi.org/10.1007/s10342-005-0076-4 


\section{Evaluation of the forest growth model SILVA along an elevational gradient in Switzerland}

Received: 12 October 2004/ Accepted: 28 July 2005/Published online: 7 September 2005

(C) Springer-Verlag 2005

\begin{abstract}
The semi-empirical single-tree model SILVA 2.2 has been developed and parameterised using forest research and inventory data from Germany that range from the colline to the montane zone. The focus of the model evaluation presented in this study was to test the applicability of the model for the main Swiss forest types and at elevations ranging from the colline to the upper subalpine zone. To this end, SILVA was initialized using data from long-term forest yield research plots. The results at the end of the 30-year simulation were compared with observed data. The analysis of the results at each test site showed that there were no significant differences in model performance between forest types. However, the deviation between simulated and observed growth depended strongly on the elevational zone, i.e., on climate. As expected, the best results were found in the colline zone, for which the model had been calibrated, whereas the upper subalpine sites revealed the strongest differences. The quality of the data regarding forest structure that were available for model initialization had a strong impact on the simulation results, mainly at high-elevation zones (i.e., supalpine and upper subalpine). We conclude that SILVA 2.2 is a suitable tool to estimate the development of single trees and standing
\end{abstract}

Communicated by Hans Pretzsch

S. Schmid $\cdot$ H. Bugmann $(\bowtie)$

Department of Environmental Sciences, ETH Zürich, Forest

Ecology, Rämistrasse 101, 8092 Zürich, Switzerland

E-mail: harald.bugmann@env.ethz.ch

Tel: +41-1-6323239

\section{A. Zingg}

Snow and Landscape Research (WSL),

Swiss Federal Institute for Forest, Zürcherstrasse 111, 8903 Birmensdorf, Switzerland

P. Biber

Chair of Forest Yield Science,

Technische Universität München, Am Hochanger 13, 85354 Freising, Germany volume for a large fraction of the forests in Switzerland. However, extreme climate conditions should be avoided with the model, and the availability of detailed stand structure information is a key priority that has a strong effect on the quality of the simulation results.

Keywords Single-tree model - Model evaluation · Site-sensitive growth modeling $\cdot$ Elevational gradient Switzerland

\section{Introduction}

Since the middle of the twentieth century, models describing the state and dynamics of forests have been applied in various fields, e.g., in forest management, in understanding ecosystem dynamics, and in the study of climate change impacts on forested ecosystems (Lischke 2001). An important aspect of any modeling effort is the evaluation of the model. Model evaluation should be an ongoing process that begins during model design and continues throughout model construction and for as long as the model remains in use (Soares 1995; Vanclay and Skovsgaard 1997). Model evaluation may involve qualitative as well as quantitative examinations of the model. These analyses mainly refer to the model logic and its theoretical and biological plausibility (qualitative examinations), as well as to the characterization of errors, model performance (Mayer and Butler 1993), and model sensitivity (Saltelli et al. 2000) (quantitative examinations). Quantitative examinations should comprise statistical tests and comparisons of model simulations with observations that are independent of those used to fit the model (Soares 1995). In the present study, an evaluation of the forest growth simulator SILVA is performed that is based on independent long-term forest survey data from Switzerland.

SILVA is a distance-dependent and environmentally sensitive single-tree model (Pretzsch 2001). It has been designed primarily to assist in the decision making process in forest management. Based on scenario calcu- 
lations it can be applied to predict the effects of silvicultural treatments, stand structure, and environmental conditions on stand development (Hanewinkel and Pretzsch 2000). Therefore, the model also serves as a research instrument and has been used in several recent studies by, among others, Pretzsch and Kahn (1996), Knoke (1998), Densborn (1999), Hanewinkel and Pretzsch (2000), Pretzsch et al. (2000), Döbbeler and Spellmann (2002), Liesebach (2002), Pretzsch and Durský (2002), and Weber (2001). Model parameterization is based on a large amount of single-tree data that are mostly from Germany (Pretzsch 2000). However, some data that were used for the calibration of the submodel capturing the growth potential of a site originate from Swiss long-term forest growth and yield research plots (Kahn 1994).

Although SILVA 2.2 and earlier model versions have already undergone several detailed evaluations (Kahn and Pretzsch 1998; Pommerening 1998; Pretzsch 1999; Windhager 1999; Pretzsch and Durský 2001; Pretzsch 2002; Pretzsch et al. 2002), the validation presented in this study is novel in several respects. Besides the general need for model testing prior to model application in a region for which the model has not been parameterized - note that the Swiss data in the model parameterization process included just a few beech stands in the colline and the lower montane zones - there are two specific reasons for these tests. (1) Model parameterization did not extend to elevations higher than the lower montane zone; however, model applications at higher zones are of large interest, since mountain forests harbor significant amounts of biomass and, thus, carbon stocks. For example, more than one third of the Swiss growing stock is located above the lower montane zone (Brassel and Brändli 1999). (2) Most of the previous tests of SILVA were based on relatively short time periods of five or ten years, while the predictive capability of the model over longer time spans is less known, although it may be of high interest in many research projects as well as in a decision-support context in practical forest management.

Therefore, the objective of the model validation presented in this study is to test the simulated growth of single trees and entire stands of the main tree species occurring in the central Alps from the colline to the upper subalpine zone, and over a comparatively long period of 30 years. In doing so, the accuracy of the model parameterization for Swiss forests and the applicability of the model under strongly varying climate conditions will be tested.

\section{Material and methods}

Forest growth model SILVA 2.2

The concept and structure of SILVA have been described in detail by Pretzsch (1992), Kahn (1994), Pretzsch and Kahn (1995), Kahn and Pretzsch (1997), Pretzsch (1997),
Pretzsch (2001), and Pretzsch et al. (2002). SILVA simulates the growth and yield of pure and mixed forests using a single-tree approach, where each tree is described by its diameter at breast height, tree height, height of the crown base, crown diameter, and stem coordinates. Species-specific spline functions and crown models are used to represent the three-dimensional stem and crown shapes (Pretzsch 1992, 2002).

The calibration of SILVA is based on the following three data sets. (1) The data for the site-growth-potential submodel of the dominant European tree species were taken from 330 long-term experimental plots ranging from the lowlands in Schleswig-Holstein (Germany) to the lower mountains of Switzerland (Kahn 1994; Pretzsch and Kahn 1998). (2) The long-term network of experimental areas maintained by the Munich Chair of Forest Yield Science provided the basis for the parameterization of all other submodels, e.g., those describing height increment, crown form, and mortality. These experimental areas are located in Bavaria, RhinelandPalatinate, and Lower Saxony (all in Germany). Based on data from 404 experimental plots, the increment model was calibrated for Norway spruce (Picea abies (L.) Karst.), European silver fir (Abies alba Mill.), Scots pine (Pinus silvestris L.), European beech (Fagus silvatica L.), Sessile oak (Quercus petraea (Matt.) Liebl.), and Black alder (Alnus glutinosa Gaertn.) (Pretzsch 2002). Some of the time series included in these datasets date back to the year 1870 (Kahn 1994). (3) Stem volume is estimated using the volume equations by Franz et al. (1973) based on data from the 1971 'large scale' Bavarian Forest Inventory. For estimating stem shape and stem-shape based timber grading, the model BDAT (Kublin and Scharnagl 1988), developed at the BadenWürttemberg Forest Research Station, was integrated into SILVA.

Since the parameterization includes only a few plots above $1,000 \mathrm{~m}$ asl, higher elevations have to be regarded as extrapolation area of the model.

In those cases where some of the initial values (diameter, tree height, height of crown base, crown diameter, and stem coordinates) for a forest stand are lacking, SILVA generates the missing data. This high flexibility with respect to model initialization is achieved by the integrated structure-generating module STRUGEN (Pretzsch 1994). STRUGEN uses the available tree attributes and a series of sophisticated algorithms to construct a realistic 3-dimensional stand structure (Pommerening 1998); among others, the algorithm for generating diameter distributions developed by Nagel and Biging (1995) is used.

SILVA simulates stand dynamics using a time step of five years. At each time step, growth and mortality of the single tree are calculated and its management is considered (Pretzsch 2002). The single-tree growth is determined by a competition index (competition between neighboring trees), an index for single-tree vitality, both of which are calculated by the model, and by nine user-defined site-specific variables (Kahn 1994; 
Pretzsch and Kahn 1998). These site variables are: soil nutrient supply (NUT), atmospheric $\mathrm{NO}_{X}\left(\mathrm{NO}_{X}\right)$ and $\mathrm{CO}_{2}\left(\mathrm{CO}_{2}\right)$ concentration, duration of the vegetation period $\left(\mathrm{DT}_{10}\right)^{1}$, annual temperature amplitude $\left(T_{\mathrm{VAR}}\right)^{2}$, mean temperature during the vegetation period ${ }^{3}\left(T_{\mathrm{V}}\right)$, aridity index of the vegetation period according to De Martonne $\left(M_{\mathrm{V}}\right)$ (De Martonne 1927), total precipitation during the vegetation period ${ }^{3}\left(P_{\mathrm{V}}\right)$, and a soil moisture factor (MOIST).

SILVA uses unimodal dose-response functions to determine the values of these nine site variables as response factors $\left(r_{1}-r_{9}\right)$ with values between 0 (minimum growth conditions) and 1 (ecological optimum of a tree species) (Fig. 1). In the case of $\mathrm{NO}_{\mathrm{X}}$ and $\mathrm{CO}_{2}$, values above $1,500 \mathrm{ppb}$ and $1,500 \mathrm{ppm}$, respectively, are highly hypothetical; but in all reasonable situations, these values are clearly beyond the range of interest (Pretzsch and Kahn 1998). Three response factors at a time are aggregated into one complex ecological factor, considering also compensation effects: nutrient supply factor $\left(r_{1}-r_{3}\right)$, thermal supply factor $\left(r_{4}-r_{6}\right)$, and water supply factor $\left(r_{7}-r_{9}\right)$. Finally, these three site-dependent ecological factors determine the course of the site-specific potential height and diameter growth functions.

SILVA provides three kinds of output variables (Pretzsch et al. 2002). Firstly, classical growth and yield data are simulated at the stand and tree level, e.g., stand basal area, mean stand height, and the diameter and height of each single tree. Secondly, monetary values can be obtained from the calculation of stand assortment distributions with the timber grading routine BDAT (Kublin and Scharnagl 1988). The third group of output information comprises indices of forest structure and diversity, e.g., the aggregation index according to Clark and Evans (1954).

\section{Experimental design}

The validation was performed at 19 test sites located in different Swiss regions. In order to render the simulation results comparable across all test sites and to minimize the effects of climatic changes at the decadal time scale, the simulations were restricted to the time window 1950-2002. SILVA was initialized with stand and site data from each test site, and stand development was simulated over a 30-year period, since this was the longest time period of observation data that was available from all test sites within this time window. For each test site, this procedure was repeated 20 times to average out stochastic influences that are inherent in the model. The average of the simulated diameter growth of each single tree during

\footnotetext{
${ }^{1}$ Days with a mean temperature of at least $10^{\circ} \mathrm{C}$.

${ }^{2}$ Difference between the highest and the lowest monthly mean temperature of the year.

${ }^{3}$ May to September, not consistent with $\mathrm{DT}_{10}$ (duration of vegetation period).
}

this time was compared with the observed diameter growth.

The focus of this quantitative test was on the model part that controls tree growth in relation to tree species, site conditions, and the individual competitive situation. Therefore, other model parts that have an indirect impact on tree growth, such as the thinning routines and the mortality submodel, were switched off for the simulations presented here. Since the data sets of the test sites provided information on the status of each single tree-i.e., alive, harvested, dead - during this 30-year time period, trees that had died or were harvested in the real stand were removed manually during the simulation.

\section{Test sites}

We used data from the forest growth and yield research plots of the Swiss Federal Institute of Forest, Snow and Landscape Research (WSL). On these plots, a wide range of aboveground single-tree data have been collected at intervals ranging from 1 to 13 years. The surveys include all trees on the plot with a diameter at breast height of at least $8 \mathrm{~cm}$. The WSL research plots are distributed all over Switzerland and cover a wide range of forest types. These long time series of single-tree growth and stand development under various environmental conditions (e.g., with respect to climate and soil characteristics) were particularly suitable for the purpose of this paper.

The simulations were conducted at 19 forest yield research plots that had not been used for model calibration efforts conducted by the model developers. The plots used here extend from the colline to the upper subalpine zone (cf. Ott et al. 1997) and cover the main Swiss forest types. The dominant tree species (with respect to basal area) on the plots (Table 1) represent the most frequent tree species in Switzerland, i.e., spruce, beech, fir, and larch (Brassel and Brändli 1999). Seven of the plots are characterized by pure stands, the others are mixed stands. Except for the test site at Horgen (no. 8), all stands are managed. The majority of the stands were between 60 and 120 years old at the beginning of the simulation period; this corresponds to a stand age distribution that is typical for Swiss forests (Brassel and Brändli 1999). The two upper subalpine stands (St. Moritz, nos. 18 and 19) are uneven-aged selection forests (so-called 'plenter' forests). Plot sizes vary between 0.2 and 1.0 ha.

On some of the forest yield research plots, the surveys did not match the desired period length of exactly 30 years. In those cases, a linear intra- or extrapolation of the observed data was needed for the comparison with the simulation results, which are available in 5-year resolution due to the time step of the model. In most cases, the time period for this inter- or extrapolation did not exceed one year. 

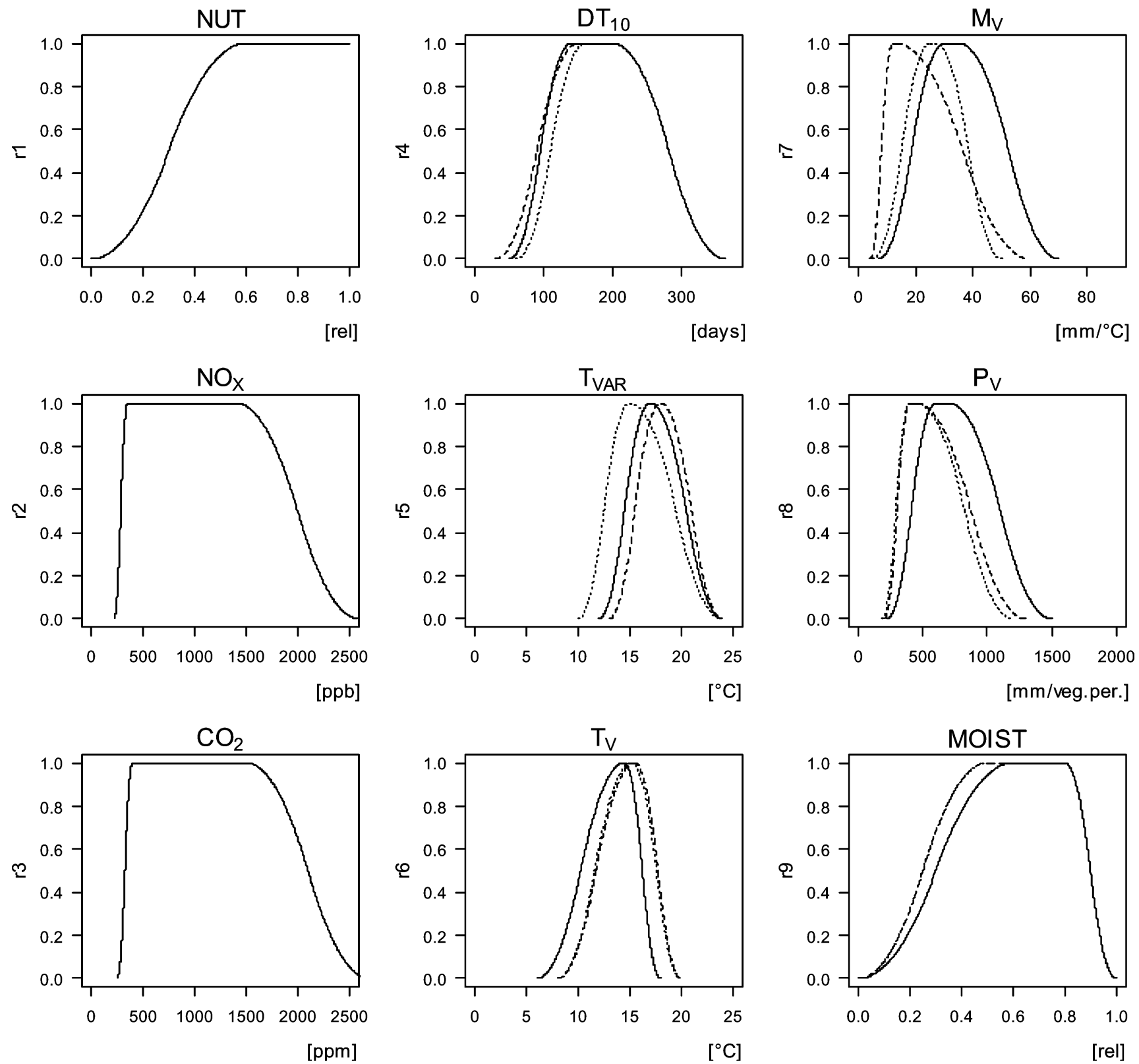

Fig. 1 Relationship between the nine site variables and their corresponding response factors $r_{1}-r_{9}$, which determine the potential height and diameter growth of trees in SILVA, shown for spruce (solid line), pine (dashed line), and beech (dotted line). NUT: soil nutrient supply, $\mathrm{NO}_{\mathrm{X}}$ : atmospheric $\mathrm{NO}_{\mathrm{X}}, \mathrm{CO}_{2}$ : atmospheric $\mathrm{CO}_{2}$, $\mathrm{DT}_{10}$ : duration of vegetation period, $T_{\mathrm{VAR}}$ : annual temperature amplitude, $T_{\mathrm{V}}$ : mean temperature during vegetation period, $M_{\mathrm{V}}$ : aridity index of the vegetation period, $P_{\mathrm{V}}$ : total precipitation during the vegetation period, MOIST: soil moisture factor

Model initialization and input data

For model initialization, we used all the available singletree information from the forest yield research plots, i.e., diameter and tree species (both available for each tree), additional single-tree data such as tree height, height of crown base, and crown diameter, as well as stem coordinates. The proportion of trees per site with additional single-tree data varied between 6 and $27 \%$, and the

proportion of trees per site with known stem coordinates varied between 0 and $100 \%$ (Table 1). Prior to the simulation, all the missing data were automatically generated by SILVA. To assess the impact of initial tree height on simulated growth, a second simulation was performed, for which the model was also initialized with the available single-tree data from the research plots, but the missing tree heights were not calculated using the SILVA-internal algorithms but using the (more precise) allometric functions derived from the Swiss National Forest Inventory (NFI) (Kaufmann 2001). Since SILVA has not been calibrated for Swiss stone pine (Pinus cembra L.) and European larch (Larix decidua Mill.), these species were replaced by Scots pine (P. silvestris L.) for the simulations.

For each forest yield research plot, the site-specific climate indices as required by SILVA were calculated 
Table 1 Overview of the test sites used to validate SILVA 2.2; underlined tree species: main tree species as given with respect to basal area. The additional single-tree data refer to tree height, height of crown base, and crown diameter

\begin{tabular}{|c|c|c|c|c|c|c|}
\hline \multicolumn{2}{|c|}{ No. Zone } & \multirow{2}{*}{$\begin{array}{l}\text { Site } \\
\text { Neuendorf }\end{array}$} & \multicolumn{2}{|c|}{$\begin{array}{l}\text { Altitude Species } \\
\text { [m asl] composition }\end{array}$} & \multicolumn{2}{|c|}{$\begin{array}{l}\text { Trees with additional Trees with stem } \\
\text { single-tree data }(\%) \text { coordi-nates }(\%)\end{array}$} \\
\hline 1 & Colline & & 470 & Spruce & 8 & 35 \\
\hline 2 & Colline & Chanéaz & 805 & Spruce/beech & 20 & 99 \\
\hline 3 & Colline & Chanéaz & 805 & Spruce/beech & 23 & 99 \\
\hline 4 & Colline & Chanéaz & 805 & Spruce/beech & 12 & 97 \\
\hline 5 & Colline & Chanéaz & 795 & Spruce/beech & 20 & 97 \\
\hline 6 & Colline & Aarburg & 475 & Beech & 22 & 98 \\
\hline 7 & Colline & Zofingen & 510 & Beech & 27 & 95 \\
\hline 8 & Colline & Embrach & 595 & Beech & 24 & 97 \\
\hline 9 & Colline & Horgen & 630 & Beech/fir & 14 & 92 \\
\hline 10 & Colline & Galmiz & 445 & Oak/beech & 10 & 48 \\
\hline 11 & Colline & Winterthur & 505 & Oak/beech & 13 & 100 \\
\hline 12 & Colline & Brittnau & 570 & Fir & 8 & 0 \\
\hline 13 & Montane & Landiswil & 960 & Spruce & 9 & 99 \\
\hline 14 & Montane & Oberhünigen & 1,050 & Spruce/fir & 17 & 72 \\
\hline 15 & Subalpine & Hospental & 1,475 & Spruce/stone 1 & 12 & 90 \\
\hline 16 & Subalpine & Morissen & 1,630 & Spruce/stone 1 & & 67 \\
\hline 17 & Subalpine & Morissen & 1,640 & Spruce/stone 1 & & 67 \\
\hline 18 & Upper subalpine & St. Moritz & 1,810 & Spruce/stone 1 & 9 & 96 \\
\hline 19 & Upper subalpine & St. Moritz & 1,810 & Spruce/stone 1 & & 96 \\
\hline
\end{tabular}

Table 2 Climate and site related input data of the 19 test sites (the aridity index $M_{\mathrm{V}}$ was calculated by the model)

NUT: soil nutrient supply; N$\mathrm{O}_{\mathrm{X}}$ : atmospheric $\mathrm{NO}_{\mathrm{X}}$ concentration [ppb]; $\mathrm{CO}_{2}$ : atmospheric $\mathrm{CO}_{2}$ concentration [ppm]; D$\mathrm{T}_{10}$ : duration of vegetation period [days]; $\mathrm{T}_{\mathrm{VAR}}$ : annual temperature amplitude $\left[{ }^{\circ} \mathrm{C}\right] ; T_{\mathrm{V}}$ : mean temperature during vegetation period $\left[{ }^{\circ} \mathrm{C}\right] ; \mathrm{M}_{\mathrm{V}}$ : aridity index; $\mathrm{P}_{\mathrm{V}}$ : total precipitation during vegetation period $[\mathrm{mm}]$; Moist: soil moisture

\begin{tabular}{lllllllllll}
\hline No. & Site & NUT & $\mathrm{NO}_{\mathrm{X}}$ & $\mathrm{CO}_{2}$ & $\mathrm{DT}_{10}$ & $T_{\mathrm{VAR}}$ & $T_{\mathrm{V}}$ & $M_{\mathrm{V}}$ & $P_{\mathrm{V}}$ & Moist \\
\hline 1 & Neuendorf & Rich & 301 & 328 & 171 & 20.1 & 15.8 & 20 & 505 & Fresh \\
2 & Chanéaz & Medium & 302 & 334 & 163 & 19.1 & 15.1 & 23 & 570 & Moist \\
3 & Chanéaz & Medium & 302 & 334 & 163 & 19.1 & 15.1 & 23 & 570 & Moist \\
4 & Chanéaz & Medium & 302 & 334 & 163 & 19.1 & 15.1 & 23 & 570 & Moist \\
5 & Chanéaz & Medium & 302 & 334 & 163 & 19.1 & 15.2 & 23 & 570 & Moist \\
6 & Aarburg & Rich & 303 & 336 & 169 & 21.1 & 15.9 & 20 & 528 & Fresh \\
7 & Zofingen & Rich & 302 & 335 & 168 & 20.8 & 15.7 & 20 & 510 & Fresh \\
8 & Embrach & Rich & 302 & 335 & 158 & 20.0 & 14.9 & 19 & 467 & Fresh \\
9 & Horgen & Rich & 302 & 334 & 169 & 20.1 & 15.5 & 27 & 692 & Fresh \\
10 & Galmiz & Rich & 303 & 336 & 177 & 20.7 & 16.7 & 14 & 377 & Fresh \\
11 & Winterthur & Rich & 304 & 342 & 166 & 20.0 & 15.5 & 19 & 485 & Fresh \\
12 & Brittnau & Medium & 302 & 332 & 163 & 20.3 & 15.3 & 20 & 510 & Fresh \\
13 & Landiswil & Moderate & 303 & 338 & 139 & 19.9 & 13.7 & 19 & 457 & Moist \\
14 & Oberhünigen & Moderate & 303 & 337 & 132 & 20.1 & 13.2 & 16 & 371 & Moist \\
15 & Hospental & Rich & 304 & 342 & 90 & 17.3 & 10.2 & 28 & 567 & Fresh \\
16 & Morissen & Medium & 303 & 337 & 95 & 18.5 & 10.7 & 29 & 598 & Fresh \\
17 & Morissen & Medium & 303 & 337 & 94 & 18.5 & 10.6 & 29 & 598 & Fresh \\
18 & St. Moritz & Medium & 304 & 340 & 67 & 20.5 & 9.0 & 24 & 454 & Fresh \\
19 & St. Moritz & Medium & 304 & 340 & 67 & 20.5 & 9.0 & 24 & 454 & Fresh \\
\hline
\end{tabular}

based on climatic data over the appropriate 30 -year time period (Table 2). Daily climate data were obtained from the monitoring network of MeteoSwiss ${ }^{4}$. Using climate data from a MeteoSwiss station close to each plot, the weather inter-extrapolation model MTCLIM 4.3 (Running et al. 1987; Thornton and Running 1999) was used to generate climate information for the specific plot. MTCLIM was designed especially for application in mountainous terrain. Global $\mathrm{NO}_{\mathrm{X}}$ content of the air and atmospheric $\mathrm{CO}_{2}$ concentration were calculated for the specific time period as recommended by Pretzsch and Kahn (1998) (Table 2). The soil data for SILVA (i.e., soil moisture and soil nutrient supply) were derived from the stand descriptions of the plots by means of the classification of the Swiss forest communities by Ellenberg and Klötzli (1972) (Table 2). For the final model input, this nominal description was translated into a

\footnotetext{
${ }^{4}$ MeteoSwiss is the national weather service of Switzerland.
}

numerical value according to Pretzsch and Kahn (1998). All these input data represent average values over the entire simulation period, and they were kept constant during the simulation.

\section{Data analysis}

\section{Single-tree level}

For the analysis of the simulated diameter increment, a number of statistical indices were used to characterize model performance. For the $i=1, \ldots, n$ trees of a given test site, the differences between the simulated diameter increments $x_{\mathrm{i}}$ and the observed ones $X_{\mathrm{i}}$ are defined as $e_{\mathrm{i}}=x_{\mathrm{i}}-X_{\mathrm{i}}$, so that

$\bar{e}=\frac{\sum_{i=1}^{n} e_{i}}{n}=\frac{\sum_{i=1}^{n}\left(x_{i}-X_{i}\right)}{n}$ 
and $\bar{e} \%=100 \cdot \bar{e} / \bar{X}$ indicate the absolute and relative bias at this site, respectively. To evaluate the distribution of the single-tree errors $e_{i}$, a measure of the precision is useful, which is defined as the standard deviation of the bias:

$s_{e}=\sqrt{\frac{\sum_{i=1}^{n}\left(e_{i}-\bar{e}\right)^{2}}{n-1}}$.

or $\mathrm{s}_{\mathrm{e}} \%=100 \cdot \mathrm{s}_{\mathrm{e}} / \bar{X}$. The distribution of the total differences between simulated and observed diameters is evaluated by the model accuracy $\mathrm{m}_{\mathrm{x}}$, which is defined as follows:

$m_{x}=\sqrt{\frac{\sum_{i=1}^{n}\left(x_{i}-X_{i}\right)^{2}}{n-1}}$.

The relative accuracy $m_{x}$ is given as $\mathrm{m}_{\mathrm{x}} \%=100 \cdot \mathrm{m}_{\mathrm{x}} / \bar{X}$. The model efficiency EF provides a comparison of the efficiency of the model simulation with the efficiency of describing the data as the mean of the observations (Mayer and Butler 1993; Smith et al. 1997), i.e.,

$$
\begin{aligned}
E F & =\frac{\sum_{i=1}^{n}\left(X_{i}-\bar{X}\right)^{2}-\sum_{i=1}^{n}\left(X_{i}-x_{i}\right)^{2}}{\sum_{i=1}^{n}\left(X_{i}-\bar{X}\right)^{2}} \\
& =1-\frac{\sum_{i=1}^{n}\left(X_{i}-x_{i}\right)^{2}}{\sum_{i=1}^{n}\left(X_{i}-\bar{X}\right)^{2}} .
\end{aligned}
$$

Another simple but efficient technique to compare simulated diameter growth with observed values is the linear regression. However, instead of using the common ordinary least squares (OLS) regression, we used reduced major axis (RMA) regression. Our goal was not to simply predict estimated growth from observed values, but to establish a linear relationship that expresses the 'true' relationship between simulation and observation. Additionally, in our case also the observed increments are subject to considerable error, which cannot be explained by SILVA. In such cases, a so-called Model II regression (Sokal and Rohlf 1995) should be applied, and RMA belongs to this class of regression methods. For the calculations we used the software RMA as provided by Bohonak (2002).

The slope $\mathrm{b}$ of the regression line $x=a+b \cdot X$ is calculated in RMA as the ratio of the standard deviations of $x$ and $X, s_{\mathrm{X}}$ and $s_{\mathrm{X}}$ :

$b= \pm \frac{s_{X}}{s_{x}}= \pm \sqrt{\frac{\sum(X-\bar{X})^{2}}{\sum(x-\bar{x})^{2}}}$

The sign of $b$ is the sign of the following sum of products:

$\sum(X-\bar{X}) \cdot(x-\bar{x})$

The intercept $a$ and the degree of determination $R^{2}$ are calculated in the same way as with OLS regression.
For a more complete description and discussion of RMA, see Sokal and Rohlf (1995) and Niklas (1994).

\section{Stand level}

In the second part of the analysis, the differences between simulated and observed stem volume increment of the whole stand were examined. Both simulated and observed stem volume (overbark bole volume) were calculated from the single-tree diameters (simulated and observed, respectively) by means of the bole volume functions derived from the Swiss NFI (Kaufmann 2001). Based on these data, we analyzed the variation of the relative differences in stem volume increment as a function of various site and stand variables. Due to the small number of test sites (19) and the lack of normality of the data distributions, it was not possible to perform detailed statistical analyses, but we had to confine ourselves to qualitative (graphical) analyses. The only quantitative statistics we applied here were Wilcoxon signed rank tests (Zar 1999) and linear RMA regression.

\section{Sensitivity analysis}

The impact of initial tree heights on simulated growth was tested on the single-tree level as well as on the stand level. To this end, we compared the results from simulations where the missing tree heights in the initialization data sets were generated by SILVA with results from simulations where the missing tree heights were calculated using the allometric functions derived from the Swiss NFI (Kaufmann 2001). The methods are based on diameterheight functions that are site-independent (SILVA height generation) and site-dependent (NFI functions), respectively. The model results were analyzed graphically and using Wilcoxon signed rank tests (Zar 1999).

\section{Results}

Single-tree level

The distribution of the relative deviations between simulated and observed diameter increments per test site revealed biases between 25.94 and $-47.03 \%$, with 15 of the 19 sites being negatively biased (all statistical indices shown here are based on simulations using the NFI functions for tree height initalization) (Table 3 and Fig. 2). This means that in general single-tree growth was underestimated by the model. Three of the lowland sites showed no significant bias $(P$-value $\leq 0.05)$. The relative precision varied between 29.99 and $77.17 \%$, and the accuracy between 32.35 and $77.18 \%$ (Fig. 2). For example, an accuracy of $32.35 \%$ means that the simulated diameter increment lies in the range of $\pm 32.35 \%$ of the real increment with a likelihood of $68 \%$, given that the differences between simulated and observed diameter increments are distributed normally, which is the case at these test sites. 
Table 3 Single-tree growth analysis based on simulations with tree heights calculated using the allometric functions derived from the Swiss NFI

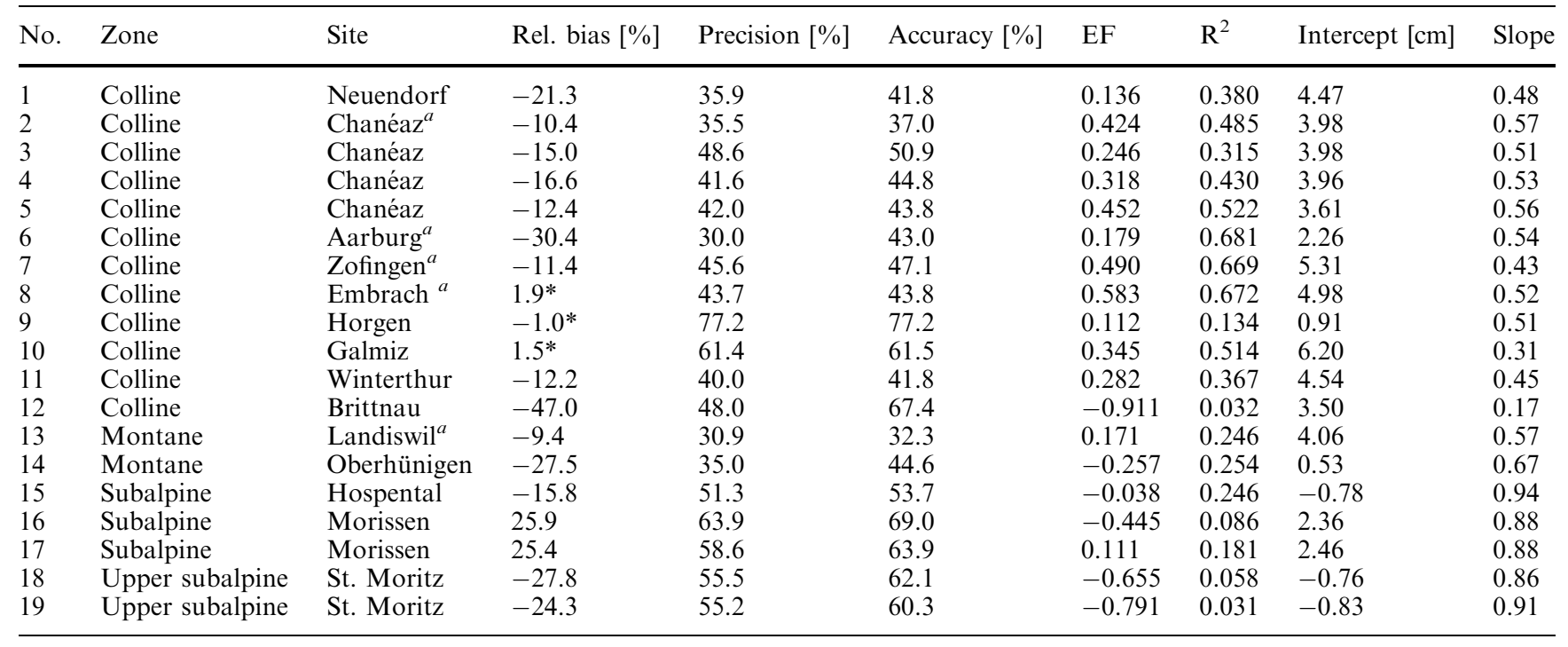

The statistical indices are calculated from the simulated and the observed diameter increment. EF: model efficiency, $\mathrm{R}^{2}$ : coefficient of determination of the linear regression between observed and simulated diameter increments. Intercept and slope refer to this regression line.

* Bias is not significantly different from zero (based on a $t$ test with $P$ value $\leq 0.05)$.

In terms of model efficiency, where a positive value indicates that the simulation describes the observed data better than the mean of the observations, SILVA provided positive values at 13 of the 19 test sites (Table 3 ). In the colline zone, only one site with a negative value was found, whereas most of the montane, subalpine, and the upper subalpine sites showed negative values.

For a more detailed analysis of the growth patterns at the different test sites, linear RMA regressions were calculated between observed and simulated single-tree diameter increments for each site. The coefficient of determination $R^{2}$ differed much among the sites, ranging from 0.031 to 0.681 , with the lowest values found in the upper subalpine zone (Table 3). The regression line of simulated versus observed diameter increment showed that in most cases the intercepts were larger, and the slopes lower than their "ideal" values of 0 and 1 , respectively. Considering also the observed absolute diameter of the single trees, we found at most sites a slight overestimation of the diameter growth of smaller trees on average, whereas the growth of larger trees was underestimated (data not shown).

Figure 3 shows the differences between observed and simulated diameter increment of spruce-dominated sites along an elevation gradient (colline, subalpine, upper subalpine zone). The growth behavior at these three sites is representative for their zone. It becomes obvious that the diameter increment of spruce is underestimated at the colline and the upper subalpine site (mainly the growth of large trees) and overestimated at the subalpine
${ }^{a}$ no significant difference in simulated diameter increment between tree height initialization by SILVA and tree height initialization using the allometric NFI functions (based on a two-sided Wilcoxon signed rank test with $P$ value $\leq 0.05)$.

site. The results also show that the different methods for generating missing tree heights (tree height generation by SILVA or tree height generation by NFI functions) had a significant impact on the simulated single-tree diameter increment at most test sites (Table 3; Wilcoxon signed rank test with $P$-value $\leq 0.05)$. However, in the colline and in the montane zone the single-tree diameter increment was much less affected by the height generation method than in the subalpine and even more so in the upper subalpine zone, where tree heights generated by SILVA led to considerably lower growth rates compared to the simulations with tree heights calculated by the NFI functions (Fig. 3; montane zone not shown). In the upper subalpine zone, also some larch trees showed increased growth when using the NFI functions instead of SILVA for tree height generation. At the subalpine and upper subalpine sites, the use of SILVA for the tree height generation led to higher and more uniform initial tree heights of spruce, larch, and stone pine compared to the heights calculated by means of the NFI functions (data not shown).

\section{Stand level}

The differences between simulated and observed stem volume increment of the whole stand after the 30-year simulation period were mainly negative (Fig. 4), indicating again that SILVA underestimated tree growth at most test sites. Only the three subalpine sites showed an 
Fig. 2 Relative bias $\bar{e}$ and relative accuracy $m_{x}$ of the simulated diameter of single trees on each of the 19 validation sites
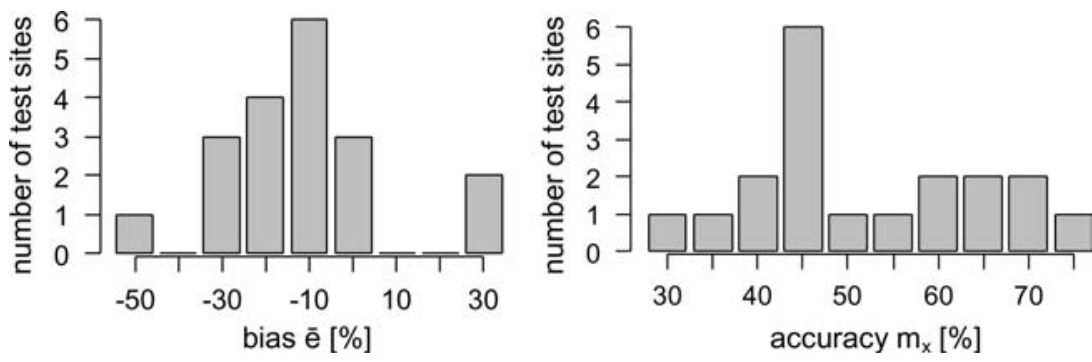

overestimation of growth. In 8 (missing tree heights calculated with NFI function) and 11 cases (missing tree heights generated by SILVA), respectively, the absolute difference was smaller than $20 \%$. Four colline sites revealed differences between -20 and $-30 \%$. The other seven and four sites, respectively, showed absolute differences of more than $30 \%$; these sites were found in the colline zone, in the subalpine zone, and in the upper subalpine zone.

The relative difference in stem volume increment between simulation and observation was found to vary strongly between zones. Although each zone was represented by only a small number of sites, significant differences in relative stem volume increment differences were found between the subalpine and the colline zones (independent of the tree height generation) and between the upper subalpine and the colline zones (only when tree heights were generated by SILVA) (Wilcoxon signed rank tests with $P$-value $\leq 0.05)$. On the stand level, the two methods did not result in significantly different stem volume increments (Wilcoxon signed rank tests with $\mathrm{p}$ value $\leq 0.05$ ).

The analysis of the possible relationships between deviations in stand growth and values of the site-specific and stand-specific variables was based on the tree height generation using the NFI functions (Fig. 5). Assuming a linear dependency between the stand growth deviation and these variables, mainly temperature and precipitation had an impact on stand growth deviation. Particularly at sites with high annual temperature amplitudes $\left(T_{V A R}\right)$, growth tended to be underestimated by SILVA. Moreover, very high and very low values, respectively, of the duration of the vegetation period $\left(\mathrm{DT}_{10}\right)$ and of the mean temperatures during vegetation period $\left(T_{\mathrm{V}}\right)$ appeared to lead to a strong growth underestimation.

\section{Discussion}

The purpose of this study was to evaluate the performance of the forest growth model SILVA 2.2 using Swiss forest data from a wide range of abiotic and biotic conditions. Since the model had been developed and parameterized mainly with forest growth data from southern Germany, we expected a good model performance in the colline and the montane zones, but possibly less so in the subalpine and upper subalpine zone. The findings of our investigation generally support these expectations.
The examination of the simulation results at the single-tree level led to the following insights (note that these results refer to simulations in which the NFI functions were used to calculate missing tree heights): at most sites, the simulated diameter increment had a negative bias (25.9 to $-47.0 \%)$ (Table 3), i.e., growth was underestimated by the model. However, three of the colline sites showed no significant bias. Compared with earlier model evaluation studies, this bias is low, particularly when taking into account the relatively long simulation period of 30 years. For example, Pretzsch (2002) found biases between 70 and $-30 \%$ after a 5 -year simulation with SILVA on 30 experimental spruce plots in Bavaria. Still, in the study by Pretzsch (2002) as well as in the present validation, most of the biases ranged between -5 and $-15 \%$. Looking at the accuracy (32.3$77.2 \%$ ) (Table 3), which considers also the distribution of the single-tree errors, the upper subalpine and subalpine sites as well as a few of the colline sites show the largest values in our study. In the study by Pretzsch (2002), accuracy values up to $48.9 \%$ were obtained after 5 years. On the one hand, these results show that there is a trend of decreasing single-tree growth performance of the model at higher elevations; this finding is also supported by the fact that the model efficiency is negative at both upper subalpine sites, at most subalpine and montane sites, but at only one site in the colline zone. On the other hand, the comparison with validation studies by other authors (e.g., Pretzsch 2002), reveals that SILVA performs quite well for the Swiss test sites, even though there is a tendency to overestimate the diameter increment of small trees and to underestimate the diameter increment of large trees.

Since the site conditions (climate and soil) are the same for all trees in the stand, the underestimation of the diameter growth of large trees seems to be caused by competition between neighboring trees that probably is overestimated in the model. Tree competition in SILVA is dependent on the distance between neighboring trees (i.e., by their stem coordinates), their heights, the heights of their crown base, and their crown diameters. The fact that diameter growth of large trees is underestimated also at sites where the stem coordinates of almost all trees are known indicates that the tree distribution by SILVA (in case of missing stem coordinates) is not responsible for this overestimation of competition. Therefore, the overestimation must be due to the initialization of the tree heights, the heights of the crown base, and the crown diameters, or it must result from the 
Fig. 3 Simulated versus observed diameter increment of single trees at the colline site Chanéaz, the subalpine site Morissen, and the upper subalpine site St. Moritz. Initial tree height calculated by SILVA (a) or by allometric functions derived from the Swiss NFI (b). Solid line: intercept $=0$ and slope $=1$; dashed line: linear RMA regression between simulated and observed diameter increment; open diamond: spruce; open circle: beech; $\mathrm{x}$ : fir; + : stone pine; open triangle: larch

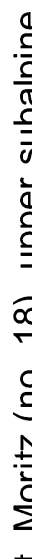

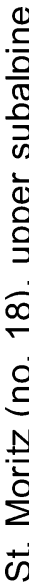
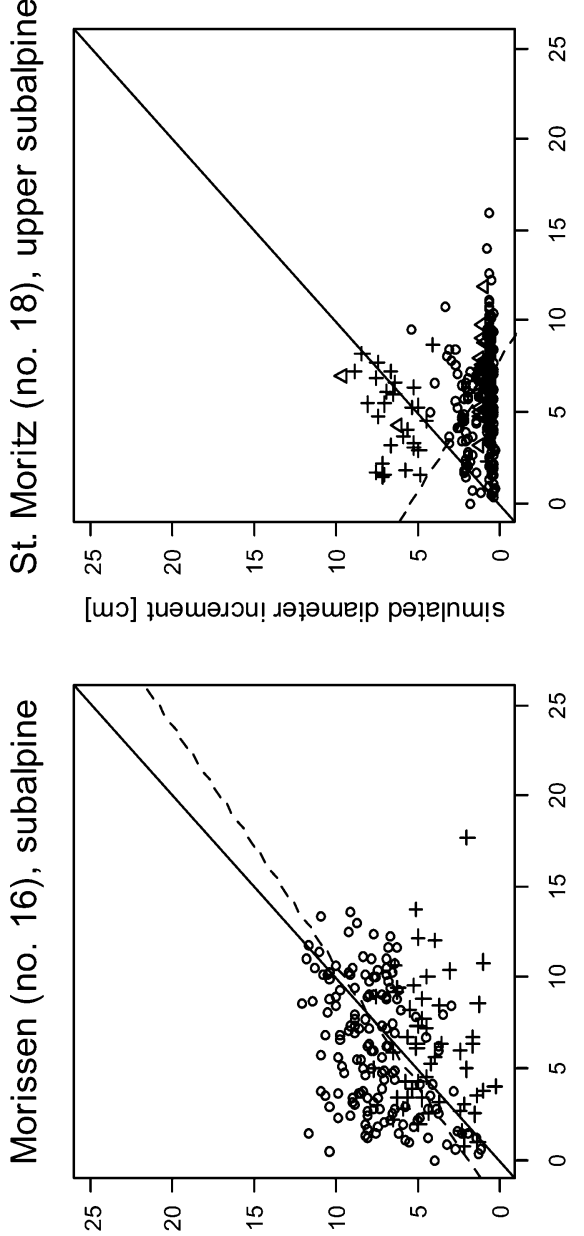

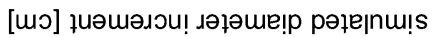

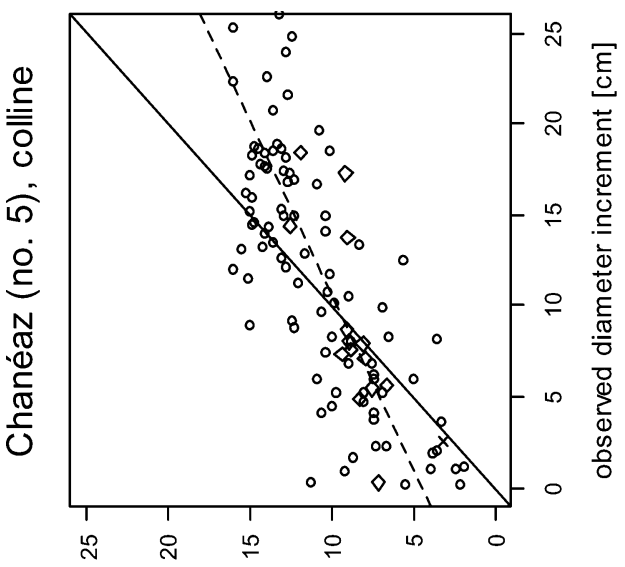

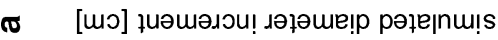

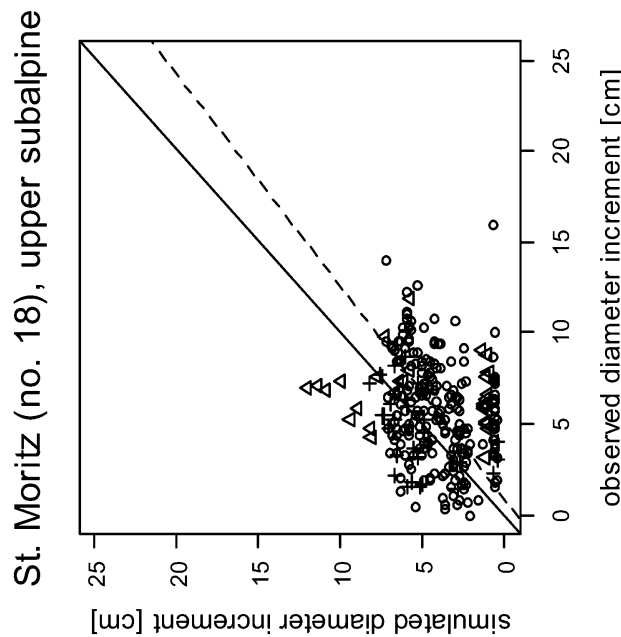

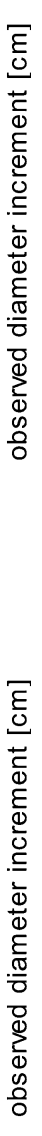

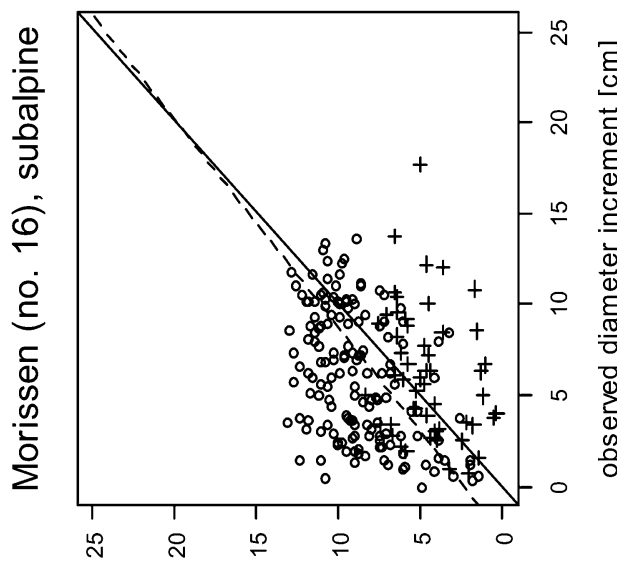

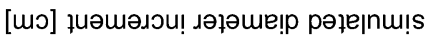

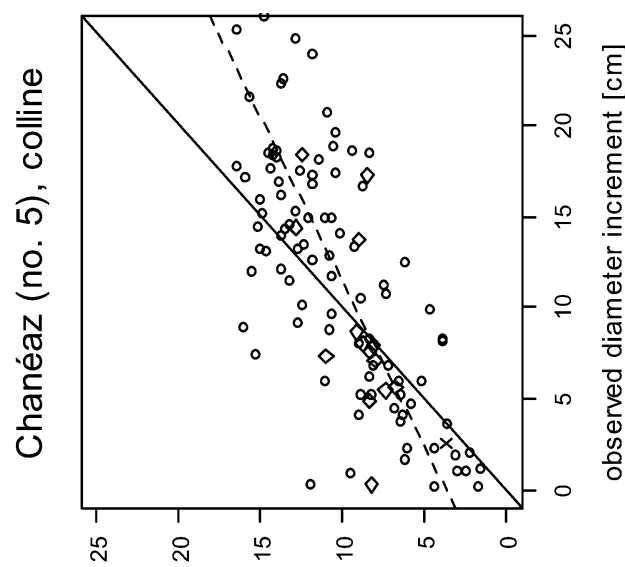

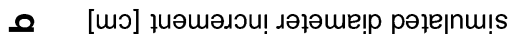

way these stand structure data are tansformed into the competition index.

The only cases where we found mostly an overestimation of the diameter growth not only of small but also of large trees were in subalpine spruce stands (Fig. 3). It is remarkable that the other tree species at these sites, stone pine, showed a clear underestimation of diameter growth. Probably the growth underestimations of stone pine trees that are too poor competitors in the simulation at these sites accumulate over the simulation period and are therefore responsible for the spruce growth overestimation. The use of the parameters of Scots pine ( $P$. silvestris) for simulating Swiss stone pine ( $P$. cembra) stands may have substantially contributed to this effect. In contrast to Swiss stone pine, Scots pine grows in the subalpine and upper subalpine zone only under very 
Fig. 4 Relative differences in stem volume increment shown for each test site (simulated increment-observed increment). Filled diamond: tree heights calculated by SILVA; filled circle: tree heights calculated by means of the allometric functions derived from the Swiss NFI

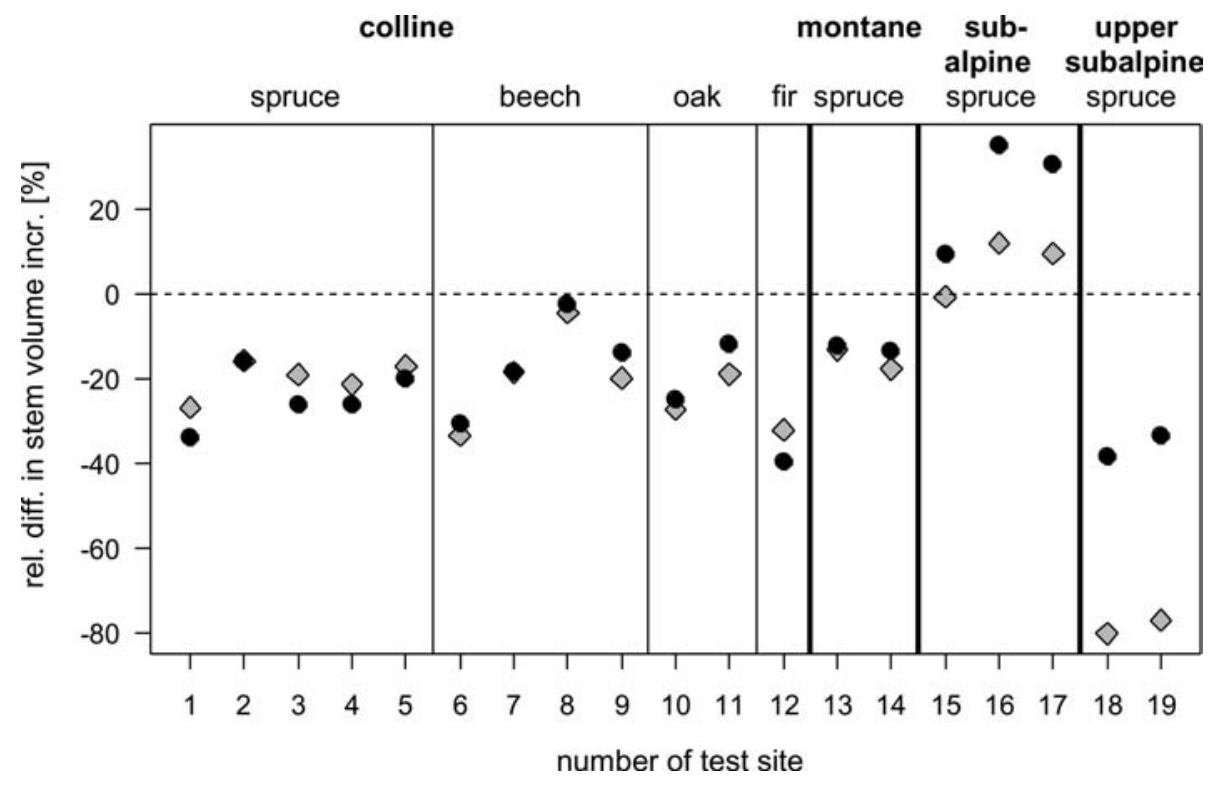

good light conditions and without strong competition from other tree species.

Our results showed that in the subalpine and even more so in the upper subalpine zone single-tree diameter increment was affected strongly by the generation of initial tree heights (Fig. 3). The single-tree heights generated by SILVA were much more uniform compared to the heights calculated by means of the allometric functions derived from the Swiss NFI. This in turn resulted in a generally smaller diameter growth of most of the trees, probably because light competition became stronger as their heights were more similar. The main reason for the differences between tree heights generated by SILVA and those calculated with the NFI functions is that SILVA does not use any site-specific information (climate, soil) to generate forest structure, whereas the NFI functions take these factors into account. Particularly at higher elevations, the height/diameter ratios of trees sometimes differ strongly from those the model was parameterized with. Therefore, it is not surprising that the largest differences in stem volume increment were found at the two uneven-aged selection forests in St. Moritz when using tree heights generated by SILVA (Fig. 4). These test sites are not only located beyond the climatic conditions for which the model had been parameterized, but they also consist of structurally heterogeneous forests where SILVA estimates single tree growth with far lower precision than in homogeneous forests (Pretzsch 2002). Although the use of the NFI functions leads to larger differences between simulated and observed stem volume increment at some sites-mainly in the subalpine zone-we prefer this method since it more accurately reflects actual stand structure.

At the stand level, the best simulation results (i.e., the smallest differences between simulated and observed stem volume increment) were found in the colline and montane zone, whereas some of the colline and subalpine sites and the two upper subalpine sites showed the largest differences (more than $\pm 30 \%$ ) (Fig. 4). Except for the three subalpine sites where growth was overestimated by SILVA, the simulated growth was always smaller than the observed one. Regarding simulated volume, our findings from the spruce sites in the colline zone agree well with the results of a comparable study with SILVA that focused on German spruce stands (Pretzsch and Durský 2001). Unfortunately, for the other zones or tree species no such comparisons could be made. However, it is obvious that some of the test sites in the colline, the montane, and the subalpine zone show very good results for a 30-year simulation on plots that have an area of only $0.2-1$ ha.

Looking at the site-specific and stand-specific variables at the 19 test sites, it becomes evident that the variables that are mainly responsible for the deviations between simulated and observed growth are those characterizing temperature and water conditions (Fig. 5). In the colline zone, particularly the high values of $\mathrm{DT}_{10}, T_{\mathrm{V}}$, and $T_{\mathrm{VAR}}$ seem to lead to an underestimation of diameter growth. Based on the results of the present as well of previous studies (e.g., Pretzsch and Durský 2001), it appears that growth underestimation of SILVA becomes stronger when simulating stands with very high site quality, particularly regarding good thermal conditions. Therefore, SILVA could potentially benefit from an improved parameterization of the growth submodel that weights the data from stands with high site quality and under the favorable climate conditions of the last decades stronger than the current parameterization. Also at the subalpine and the upper subalpine sites, the temperature-related climate variables play a major role. The growth overestimation at the subalpine sites seems to be strongly related to the relatively low values of $T_{\mathrm{VAR}}$ that lead to a large growth rate of spruce (response factor close to 1). In the upper subalpine zone, high $T_{\mathrm{VAR}}$ values as well as very low 

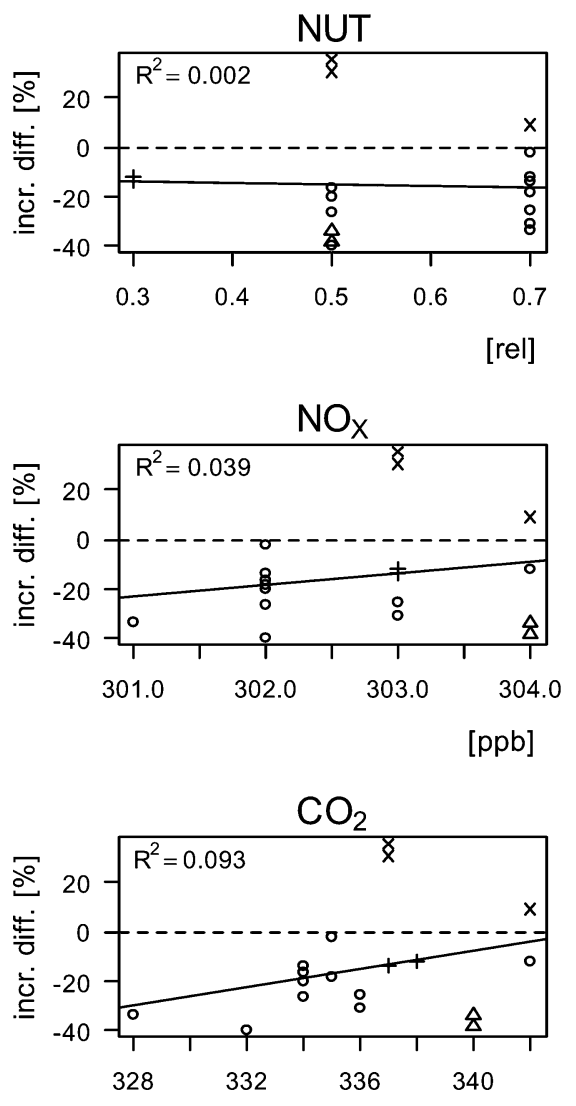

[mm/veg.per.]

single tree data

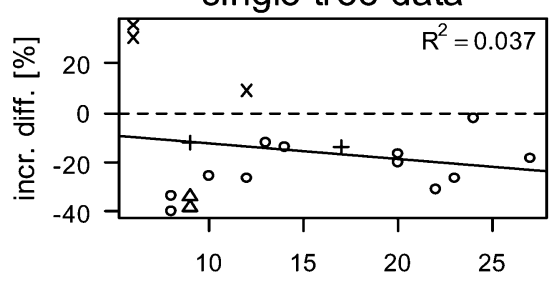

[\%]

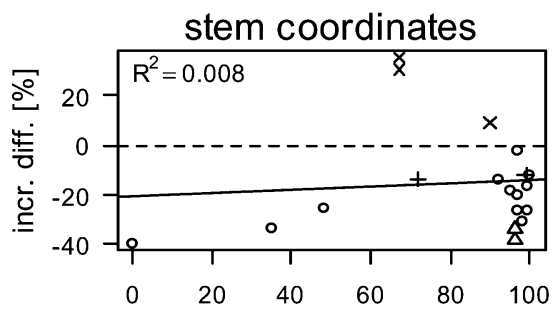

[\%]
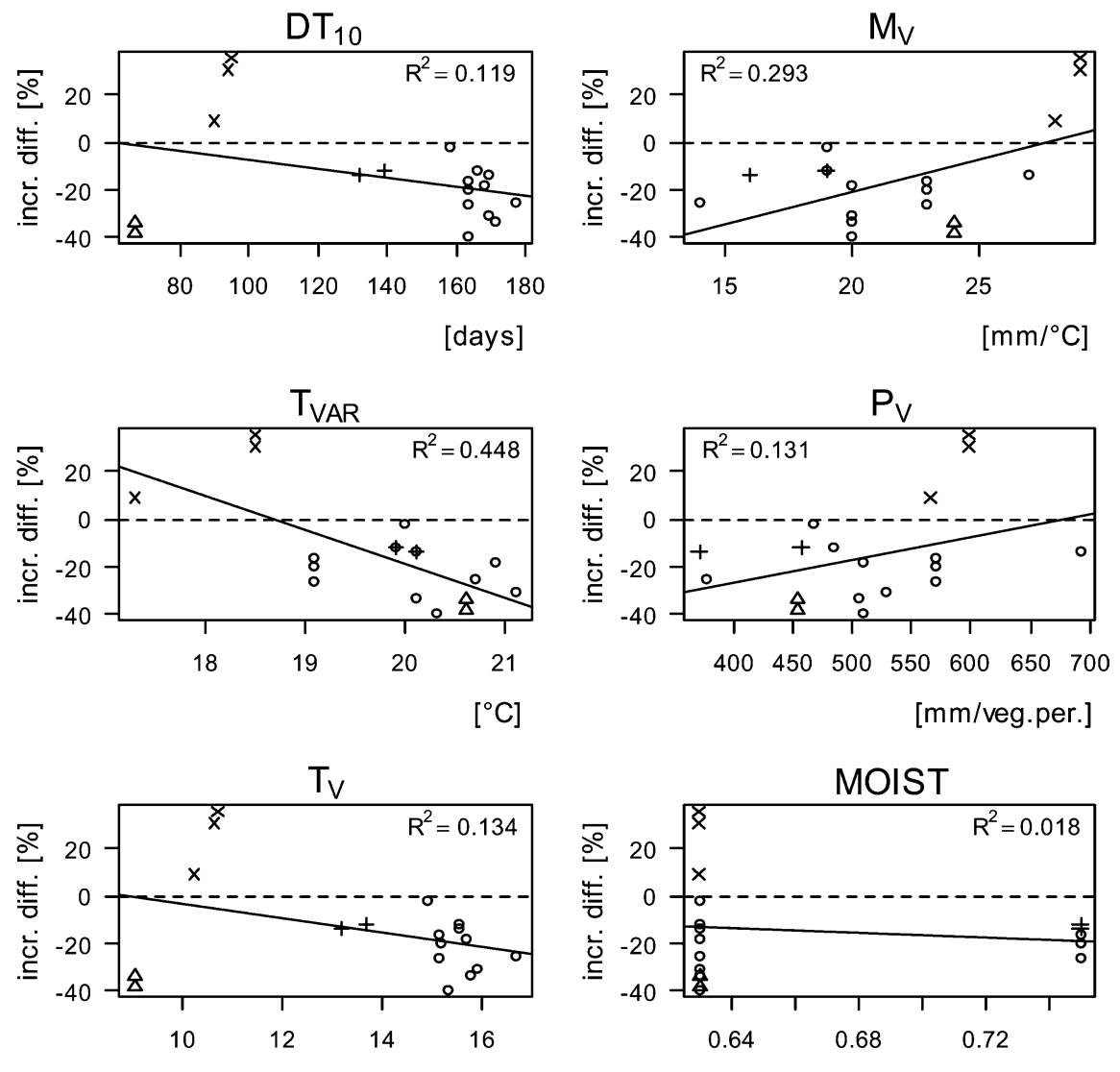

$\left[{ }^{\circ} \mathrm{C}\right]$

$\left[{ }^{\circ} \mathrm{C}\right]$
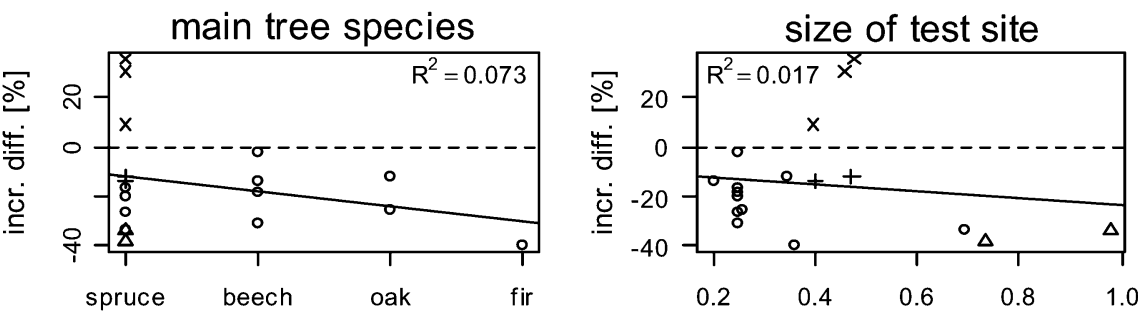

[ha]
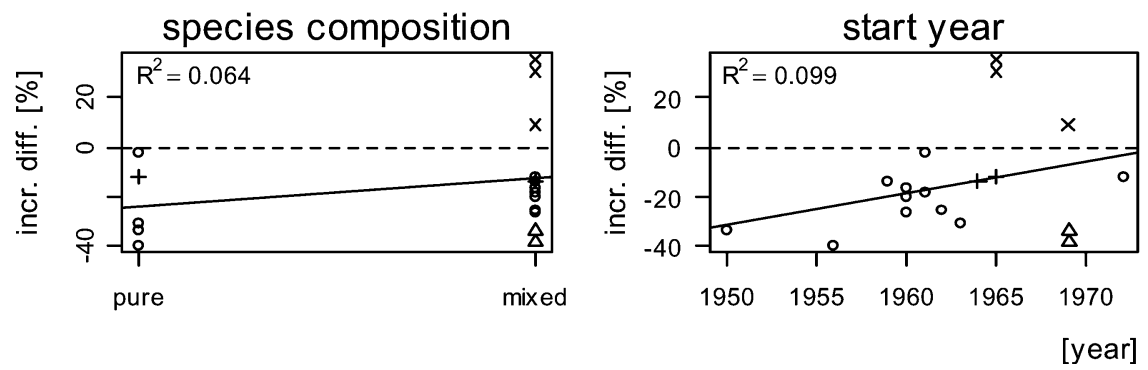

Fig. 5 Relative differences in stem volume increment (simulated increment-observed increment) plotted against the nine site variables, the proportion of trees per site with additional singletree data (tree height, height of crown base, and crown diameter) (Table 1), the proportion of trees per site with known stem

coordinates (Table 1), the main tree species (Table 1), the species composition (Table 1), the size of the test site, and the start year of the simulations. open circle: colline; + : montane; $\mathrm{x}$ : subalpine; open triangle : upper subalpine; dashed line: zero line; solid line: 
$\mathrm{DT}_{10}$ and $T_{\mathrm{V}}$ values appear to be responsible for the strong underestimation of growth.

\section{Conclusions}

Although this model validation is based on only 19 test sites, and in spite of the fact that the results are valid only for the climate and site conditions under which the model was tested, some conclusions can be drawn regarding the applicability of SILVA 2.2 in Switzerland. For the use of the current version of the model, two main factors need to be considered: (1) climate conditions and (2) the availability - or in case of missing data, the generation - of stand structure information. Regarding climate, zones with an extreme climate regime should be avoided, e.g., continental climates or those towards the upper treeline. In general, mainly sites with high $T_{\text {VAR }}$ values seem to be critical and may lead to invalid simulation results. Concerning stand structure information, all of the available single tree information should be used and - if possible - missing values should be calculated by means of allometric functions that are valid for the corresponding zone, because it appears to us that the structure-generating submodel of SILVA is quite general, but of low local precision. Mainly at high elevations (i.e., in our study the subalpine and upper subalpine zones) in the case of highly heterogeneous stands, this aspect becomes increasingly important, and may have a decisive influence on the simulation results. Based on these findings, we conclude that under optimal conditions (i.e., no extreme climate, sound stand structure information for model initialization), the main Swiss tree species and species compositions can be simulated adequately with SILVA 2.2, even in zones above $1,000 \mathrm{~m}$ asl, i.e., in an area that the model has not been parameterized for.

Acknowledgements This study is part of the project "Carbon Pools and Fluxes in Swiss Forests: A Quantitative Assessment for the Present and the 21th Century" and has been funded by the Swiss Agency for the Environment, Forests, and Landscape (BUWAL). We thank Ralf Moshammer (TU München) for support during large-scale simulation runs.

\section{References}

Akça A (1997) Waldinventur. Cuvillier, Göttingen Arbeitskreis Standortkartierung (1985) Forstliche Wuchsgebiete und Wuchsbezirke in der Bundesrepublik Deutschland. Landwirtschaftsverlag, Münster Hiltrup

Bohonak AJ (2002) RMA. Software for Reduced Major Axis Regression. v114b. San Diego State University. Software and documentation available online at http://www.bio.sdsu.edu/ pub/andy/rma.html

Brassel P, Brändli U-B (1999) Schweizerisches Landesforstinventar: Ergebnisse der Zweitaufnahme 1993-1995. Paul Haupt Verlag, Bern

Brassel P, Lischke H (eds) (2001) Swiss national forest inventory: methods and models of the second assessment. Swiss Federal Research Institute WSL, Birmensdorf
Clark PJ, Evans FC (1954) Distance to nearest neighbour as a measure of spatial relationships in populations. Ecology 35(4):445-452

De Martonne E (1927) Regions of interior-basin drainage. Geogr Rev 17(3):397-414

Densborn S (1999) Betriebssimulation-Instrument für die strategische Planung im Forstbetrieb. Fallstudie Kiefernbetriebsklasse 'Pfälzerwald' und Analyse der Funktionen von Simulatoren im Planungsprozess. Dissertation an der Forstwissenschaftlichen Fakultät der Albert-Ludwigs-Universität Freiburg

Döbbeler H, Spellmann H (2002) Methodological approach to simulate and evaluate silvicultural treatments under climate change. Forstwissenschaftliches Centralblatt 121 (Suppl 1):52-69

Durský J (1997) Modellierung der Absterbeprozesse in Rein- und Mischbeständen aus Fichte und Buche. Allgemeine Forst und Jagdzeitung 168:131-134

Ellenberg H, Klötzli F (1972) Waldgesellschaften und Waldstandorte der Schweiz. Mitt Eidg Forsch Anst f Wald Schnee und Landschaft 48(4):589-930

Franz F, Bachler J, Deckelmann B, Kennel E, Kennel R, Schmidt A, Wotschikowsky U (1973) Bayerische Waldinventur 1970/71, Inventurabschnitt I: Grossrauminventur Aufnahme- und Auswertungsverfahren. Forstliche Forschungsberichte München, Bd 11

Hanewinkel M, Pretzsch H (2000) Modelling the conversion from even-aged to uneven- aged stands of Norway Spruce (Pices abies L. Karst.) with a distance-dependent growth simulator. For Ecol Manage 134:55-70

Kahn M (1994) Modellierung der Höhenentwicklung ausgewählter Baumarten in Abhängigkeit vom Standort. Forstliche Forschungsberichte München, Bd 141

Kahn M, Pretzsch H (1997) Das Wuchsmodell SILVA-Parametrisierung der Version 2.1 für Rein- und Mischbestände aus Fichte und Buche. Allgemeine Forst Jagdzeitung 168(6-7):115123

Kahn M, Pretzsch H (1998) Parametrisierung und Validierung des Wuchsmodells SILVA 2.2 für Rein- und Mischbestände aus Fichte, Tanne, Kiefer, Buche, Eiche und Erle. Deutscher Verband Forstlicher Forschungsanstalten, Sektion Ertagskunde, Jahrestagung vom 25.-27. Mai 1998 in Kevelaer: 18-34

Kaufmann E (2001) Estimation of standing timber, growth and cut. In: Brassel, P. and Lischke, H. (eds) Swiss national forest inventory: methods and models of the second assessment. Birmensdorf, Swiss Federal Research Institute WSL, pp 162-198

Knoke T (1998) Analyse und Optimierung der Holzproduktion in einem Plenterwald - zur Forstbetriebsplanung in ungleichaltrigen Wäldern. Forstliche Forschungsberichte München, Bd 170

Kublin E, Scharnagl G (1988) Verfahrens- und Programmbeschreibung zum BWI- Unterprogramm BDAT. Forstliche Versuchs- und Forschungsanstalt Baden- Württemberg, Freiburg i. Breisgau

Liesebach M (2002) On the adaptability of Norway spruce (Picea abies (L.) Karst.) to the projected change of climate in Germany. Forstwissenschaftliches Centralblatt 121(Suppl 1):130144

Lischke H (2001) New developments in forest modeling: Convergence between applied and theorerical approaches. Nat Resource Model 14(1):71-102

Mayer DG, Butler DG (1993) Statistical validation. Ecol Model 68:21-32

Nagel J, Biging GS (1995) Schätzung der Parameter der Weibullfunktion zur Generierung von Durchmesserverteilungen. Allgemeine Forst und Jagdzeitung 166:185-189

Niklas KJ (1994) Plant allometry. The scaling of form and process. The University of Chicago Press, Chicago, $395 \mathrm{pp}$

Ott E, Frehner M, Frey HU, Lüscher P (1997) Gebirgsnadelwälder: Ein praxisorientierter Leitfaden für eine standortgerechte Waldbehandlung

Pommerening A (1998) Fortschreibung von Stichprobendaten mit positionsabhängigen Wuchsmodellen. Tagungsbericht der Jahrestagung 1998 der Sektion Ertragskunde im Deutschen 
Verband Forstliche Forschungsanstalten. Lehrstuhl für Waldwachstumskunde der Ludwig-Maximilians-Universität München/Freising, pp 35-51

Pretzsch H (1992) Konzeption und Konstruktion von Wuchsmodellen für Rein- und Mischbestände. Forstliche Forschungsberichte München, Bd 115

Pretzsch H (1994) Analyse und Reproduktion räumlicher Bestandesstrukturen. Versuche mit dem Strukturgenerator STRUGEN. Schriften aus der Forstlichen Fakultät der Universität Göttingen, Bd 114

Pretzsch H (1997) Analysis and modeling of spatial stand structures. Methodological considerations based on mixed beech-larch stands in Lower Saxony. For Ecol Manage 97(3):237-253

Pretzsch H (1999) Zur Evaluierung von Wuchsmodellen. Tagungsbericht der Jahrestagung1999 der Sektion Ertragskunde im Deutschen Verband Forstliche Forschungsanstalten. Lehrstuhl für Waldwachstumskunde der Ludwig-Maximilians-Universität München/Freising, pp 1-23

Pretzsch H (2001) Modellierung des Waldwachstums. Blackwell Wissenschaftsverlag, Berlin, $341 \mathrm{pp}$

Pretzsch H (2002) Application and evaluation of the growth simulator SILVA 2.2 for forest stands, forest estates and large regions. Forstwissenschaftliches Centralblatt 212 (Suppl 1):28-51

Pretzsch H, Durský J (2001) Evaluierung von Waldwachstumssimulatoren auf Baum- und Bestandesebene. Allgemeine Forst Jagdzeitung 172(8/9):146-150

Pretzsch H, Durský J (2002) Growth reaction of Norway Spruce (Pices abies (L.) Karst.) and European Beach (Fagus silvatica L.) to possible climatic changes in Germany. Forstwissenschaftliches Centralblatt 121(Suppl 1):145-154

Pretzsch H, Kahn M (1995) Modelling growth of Bavarian mixed stands in a changing environment. In: Caring for the forest: research in a changing world. Congress report, vol II. IUFRO XX world congress, 6-12 August 1995, Tampere, Finland, pp $234-247$

Pretzsch H, Kahn M (1996) Variantenstudie Fichtenreinbestand versus Fichten/Buchen- Mischbestand. Allgemeine Forst Zeitschrift 51(25):1415-1419

Pretzsch H, Kahn M (1998) Forschungsvorhaben "Konzeption und Konstruktion von Wuchs- und Prognosemodellen für Mischbestände in Bayern"“. Abschlussbericht Projekt W 28, Teil
2. Konzeption und Konstruktion des Wuchsmodells SILVA 2.2. Lehrstuhl für Waldwachstumskunde, Ludwig-MaximiliansUniversität, München

Pretzsch H, Dursky J, Pommerening A, Fabrika M (2000) Waldwachstum unter dem Einfluss grossregionealer Standortsveränderungen. Forst und Holz 55(10):307-314

Pretzsch H, Biber P, Durský J (2002) The single tree-based stand simulator SILVA: construction, application and evaluation. For Ecol Manage 162: 3-21

Running SW, Nemani RR, Hungerford RD (1987) Extrapolation of synoptic meteorological data in mountainous terrain and its use for simulating forest evapotranspiration and photosynthesis. Can J For Res 17(5):472-483

Saltelli A, Chan K, Scott EM (2000) Sensitivity Analysis. Wiley, Chichester, $475 \mathrm{pp}$

Smith P, Smith JU, Powlson DS, McGill WB, Arah JRM, Chertov OG, Coleman K, Franko U, Frolking S, Jenkinson DS, Jensen LS, Kelly RH, Klein-Gunnewiek H, Komarov AS, Li C, Molina JAE, Mueller T, Parton WJ, Thornley JHM, Whitmore AP (1997) A comparison of the performance of nine soil organic matter models using datasets from seven long-term experiments. Geoderma 81:153-225

Soares P, Tomé M, Skovsgaard JP, Vanclay JK (1995) Evaluating a growth model for forest management using continuous forest inventory data. For Ecol Manage 71(3):267-274

Sokal RR, Rohlf FJ (1995) Biometry : the principles and practice of statistics in biological research, 3 edn. Freeman, New York, $887 \mathrm{pp}$

Thornton PE, Running SW (1999) An improved algorithm for estimating incident daily solar radiation from measurements of temperature, humidity, and precipitation. Agric For Meteorol 93:211-228

Vanclay JK, Skovsgaard JP (1997) Evaluating forest growth models. Ecol Model 98:1-12

Weber M (2001) Kohlenstoffspeicherung in Lenga (Nothofagus pumilio) Primärwäldern Feuerlands und Auswirkungen ihrer Überführung in Wirtschaftswald auf den C-Haushalt, Verlag Dr. Norbert Kessel, Remagen-Oberwinter, 119 pp

Windhager M (1999) Evaluierung von vier verschiedenen Waldwachstumssimulatoren. Dissertation an der Universität für Bodenkultur, Wien, $216 \mathrm{pp}$

Zar JH (1999) Biostatistical Analysis, 4th edn. Prentice-Hall, London, $663 \mathrm{pp}$ 